\title{
Circulaciones literarias. La poesía de Federico García Lorca como paradigma de la literatura mundial
}

\author{
KIRSTEN KRAMER
}

(Universität Bielefeld)

\section{INTRODUCCIÓN}

La poesía española de gran parte del siglo xx está marcada por múltiples entrelazamientos, conexiones y circulaciones transnacionales que determinan las modalidades de su recepción dentro y fuera del espacio cultural europeo. Estas dinámicas se documentan con mayor evidencia en la producción lírica de la llamada generación del 27 y notablemente en la obra poética de Federico García Lorca, que, por su amplio reconocimiento internacional, frecuentemente se describe como un ejemplo paradigmático de lo que en los debates actuales se concibe como world literature o "literatura mundial”. Ya la publicación simultánea de la colección lírica Poeta en Nueva York en 1940 en México y en Nueva York, así como la publicación del Romancero gitano en 1928 en la célebre edición de la Revista de Occidente, de conocida reputación tanto en Europa como en varios países de América Latina, documentan la extensa difusión internacional de la producción lírica de Lorca. Mientras que la publicación del Romancero tuvo rápidamente un inmenso éxito entre el público europeo y latinoamericano, el ciclo Poeta en Nueva York, por el contrario, fue recibido con una ambivalencia notable, resultado de la "accidentada transmisión" del texto incompleto (que subsiste hasta hoy día en diferentes ediciones, parcialmente contradictorias), como también de la complejidad del lenguaje poético y de las circunstancias del asesinato del autor. ${ }^{1}$ Estos factores, en su conjunto, favorecieron las lecturas identificatorias y biografistas

${ }^{1}$ Acerca de la recepción de la producción lírica de García Lorca y la historia de la edición de Poeta en Nueva York, véanse, entre otros, Eisenberg 1976: 27-175; GarcíaPosada 1981; Millán 1998: 19-53; Koppenfels 1998: 10-19. Sobre la recepción internacional del Romancero, véase, de modo ejemplar, Siebenmann 1998b. 
que dominaron durante muchos años la recepción crítica de su obra. Sin embargo, estudios más recientes han destacado que la poesía de Lorca consiguió suscitar profundos cambios en la cultura poética de diversos países latinoamericanos, lo que allanó el terreno para una recepción más extensiva de la literatura de la vanguardia (europea). ${ }^{2}$

Además, la difusión de los textos forma parte de amplias dinámicas espaciotemporales de circulación y migración de formas literarias que en la generación del 27 originariamente se derivan en gran medida de la recepción de la lírica de Góngora, a la que el grupo de poetas debe su propia formación. Como ha señalado notablemente el crítico alemán Hans Ulrich Gumbrecht (1982), Góngora tiene una importancia central para los poetas de comienzos del siglo xx en la medida en la que el recurso a su poesía permite a los autores, por un lado, establecer un vínculo estrecho con la cultura popular del pasado español (cuyo modelo sigue el Romancero gitano) y, por otro, conectar esta referencia al pasado nacional con formas poéticas innovadoras y experimentales que dentro de la producción literaria de la generación del 27 se combinan frecuentemente con técnicas de representación poética, derivadas de los movimientos vanguardistas característicos de la Modernidad europea.

Parece legítimo, por lo tanto, leer la poesía de Lorca como la articulación de una world literature o "literatura mundial" que, según los debates actuales, se define no solamente por su difusión internacional, favorecida por complejos procesos de selección normativa y canonización jerárquica, sino que, además, se presenta como un modo literario particular definido por múltiples interconexiones, migraciones y circulaciones transculturales de conceptualizaciones del mundo, de formas de saber y modos de enunciación que, en su conjunto, llegan a constituir la "mundialidad" específica de la literatura. A partir de una breve sinopsis de planteamientos actuales articulados en el debate dedicado al concepto de Weltliteratur, este ensayo se propone investigar - en el marco de la lectura ejemplar de un texto poético del ciclo Poeta en Nueva York- de qué modo la producción lírica de Lorca articula por medio de sus propias técnicas de representación las dinámicas de circulación, "traducción" e interacción de géneros, objetos, actores y modos de saber que contribuyen en gran parte a formar la "literatura mundial" de las primeras décadas del siglo xx. Cabe destacar que, dentro de la poesía de Lorca, la confrontación estética con fenómenos (trans)culturales tan diversos como la lírica de Góngora, la vanguardia surrealista (cinematográfica y literaria), el jazz o el teatro barroco, además de los numerosos cambios espaciotemporales de la situación de enunciación, llegan a generar esta "mundialidad" específica en su

${ }^{2}$ Para una descripción extensa del impacto ejercido por la lírica de Lorca en varios paises de América Latina, véanse Siebenmann 1998a y 1998b. 
poesía, que, posiblemente, favorece su recepción tanto dentro como fuera del espacio de la cultura ibérica.

\section{El CONCEPTO DE WORLD LITERATURE: PERSPECTIVAS E IMPLICACIONES TEÓRICAS}

En los debates actuales de los estudios culturales se ha formado una conceptualización de la world literature definida por un distanciamiento parcial del concepto de canonización estética basado en procesos de selección literaria y crítica que, con frecuencia, confiere a los textos y géneros pertenecientes a la "literatura mundial" un estatus eminentemente normativo y que va retomando - como lo sugieren ocasionalmente los trabajos del crítico norteamericano David Damrosch $-{ }^{3}$ algunas de las paradojas que forman la base de la privilegización de la "alta literatura", representada por las élites (y opuesta a la literatura popular). Como ha destacado en particular Franco Moretti en sus conocidas reflexiones dedicadas al concepto de literatura mundial (Moretti 2000 y 2003), precisamente en sus "formas" estéticas, la literatura puede ser concebida como una "relación social" (Moretti 2000: 6) que, en conformidad con las hipótesis centrales de la world systems theory formuladas por Immanuel Wallerstein (2004), se puede asimilar a las dinámicas de organización de sistemas sociales y técnicos que, por su parte, se someten formalmente a las mismas leyes que definen la evolución biológica, el mercado económico y la emergencia de ámbitos y sistemas informacionales del mundo actual. En una perspectiva semejante, la crítica alemana - representada, entre otros, por Ottmar Ette o Erhard Schüttpelz - se vale de los planteos de la historia universal formulados por Fernand Braudel (1988) y define la world literature como literatura mundo, que se distingue de manera estructural y categórica de una literatura mundial caracterizada por su mera propagación o difusión por el mundo internacional (Schüttpelz 2009). Esta literatura mundo o global se inscribe en el amplio contexto de los complejos procesos de globalización cultural que no determinan solamente las sociedades actuales de los siglos xx y xxI, sino que también marcan varias fases históricas de aceleración y de migración (cf. Ette 2012; Schüttpelz 2009) que poseen sus propios centros globales y periferias locales, sus propios modos de operación social y estrategias de legitimación cultural y que, si no se ubican desde la perspectiva de una longue durée ya en épocas prehistóricas (tal como la migración "global” del homo sapiens desde África a Asia y Eura-

${ }^{3}$ Estos procesos de selección crítica se evidencian notablemente en las referencias frecuentes al estudio de "textos literarios clásicos". Véanse, entre otros, Damrosch 2009 y 2014. 
sia), provienen, por lo más tarde, de la época de la temprana Modernidad (con sus dinámicas europeas de expansión territorial y política hacia las Américas) y llegan, así, a implantar complejas interconexiones transculturales entre el presente y el pasado.

Además, la world literature se caracteriza por una "mundialidad” específica: su extensión en dimensiones globales se evidencia frecuentemente en el esbozo de topografías literarias que intentan captar el mundo en su totalidad geográfica o cultural y que a menudo no se limitan a trazar la conectividad de las técnicas modernas de transporte y de comunicación, sino que contribuyen a delinear complejos espacios narrativos o poéticos de orientación no lineal. ${ }^{4}$ Desde esta perspectiva, la "literatura mundial" se presenta como el lugar de una "dinamización” de distintos órdenes del mundo y formas de saber, como también de géneros literarios y modos de enunciación poética que logran explorar de modo experimental las lógicas y los sistemas de circulación de los saberes del mundo en contextos culturales, sociales y políticos muy diversos. La world literature, por ende, obtiene el estatus de un concepto programático central que sirve para denotar tanto una práctica discursiva crítica como un "proyecto epistemológico” - en la terminología empleada por Djelal Kadir (2013: 294)— que intenta captar el vínculo entre literatura y mundo real por medio de una transferencia de la movilización dinámica de personas, objetos y signos, que marca la organización del mundo global empírico, en procesos específicamente estéticos de interconexión, circulación o "traducción" translocal de formas de saber y de articulación poética. Estos procesos, por lo tanto, no afectan solamente a la extensión o difusión de ciertos fenómenos literarios por el mundo geográfico global (que se evidencian, por ejemplo, en las transformaciones que marcan la recepción de la novela policíaca en contextos nacionales o culturales diversos), sino que se manifiestan igualmente en las técnicas poéticas de poiesis o construcción de este mundo (que representan prácticas del worlding, según la terminología de Djelal Kadir). ${ }^{5}$ Las operaciones de esta poiesis remiten tanto a los orígenes míticos o cosmológicos de la literatura y a sus articulaciones orales o escritas como a los movimientos migratorios, las trayectorias de difusión y transmisión y los centros de comunicación que, en su interacción histórica, solo llegan a conferir a los sistemas literarios su verdadera dimensión mundial.

${ }^{4}$ Para una descripción diferenciada de formas y funciones culturales de la construcción estética de tales espacios literarios, véanse las observaciones pertinentes en Honold 2010.

${ }^{5}$ Según Kadir, el verbo world, que remite al empleo heideggeriano del término, denota tanto las técnicas poéticas de la world literature como los discursos teóricos formulados por la crítica. Acerca de las diversas conotaciones del término, véase Kadir 2004. 


\section{Mundialidad y worlding en Poeta en Nueva York}

Estos procesos de interconexión y circulación de formas de saber, géneros literarios y técnicas de representación marcan, asimismo, la producción lírica de Lorca, en la que se evidencian distintas técnicas de un worlding transcultural que contribuyen a constituir el carácter específicamente "mundial" de su poesía. Dentro de la producción lírica, el Romancero gitano se distingue por la difusión internacional más extensiva. Se trata de un texto que, por una parte, documenta el interés del autor en la poesía popular tradicional y que se puede leer como articulación de un "neopopularismo" moderno y transcultural repartido en España y en varios países latinoamericanos. ${ }^{6}$ Por otra parte, el Romancero está marcado por el empleo de formas de lenguaje experimentales que permiten ubicar el texto en el ámbito de la poesía de las vanguardias. ${ }^{7}$

Ahora bien, en Poeta en Nueva York (empezado en 1929 y publicado de modo póstumo en 1940) se manifiesta una orientación estética notablemente diferente, ya que se trata de una poesía dedicada a descripciones de la metrópolis (en la tradición baudelairiana) y que, por lo tanto, representa un género específicamente moderno, cuyas técnicas de construcción del mundo o del worlding se analizarán de modo ejemplar con el poema "Ciudad sin sueño (Nocturno del Brooklyn Bridge)". En este texto, la lírica gongorina proporciona un marco de referencia central para los procesos de circulación de formas literarias que determinan la dinámica de poiesis del mundo realizado a lo largo de todo el poema. No obstante, la poesía de Góngora no supone el punto de partida para la confrontación estética con el pasado nacional, sino que sirve notablemente para iniciar nuevos modos de percepción visual conformadores de una visión estética que, por su parte, constituye el paradigma formal para las técnicas de representación y descripción poética eminentemente innovadoras.

\section{CIUDAD SIN SUEÑO \\ (Nocturno del Brooklyn Bridge)}

No duerme nadie por el cielo. Nadie, nadie.

No duerme nadie.

Las criaturas de la luna huelen y rondan sus cabañas.

Vendrán las iguanas vivas a morder a los hombres que no sueñan

"Acerca de lecturas críticas del "neopopularismo" de Lorca, que se sitúa en el marco de referencia de la experiencia cultural de la modernidad, véanse las concisas observaciones de Koppenfels 1998: 5-9; con respecto a variantes latinoamericanas del "neopopularismo", véase Siebenmann 1998a.

${ }^{7}$ Sobre esta ambivalencia, que se evidencia notablemente en el empleo del género tradicional del romance en el Romancero gitano, véanse las instructivas observaciones de Dirscherl 1987. 
5 y el que huye con el corazón roto encontrará por las esquinas al increíble cocodrilo quieto bajo la tierna protesta de los astros.

No duerme nadie por el mundo. Nadie, nadie.

No duerme nadie.

Hay un muerto en el cementerio más lejano

10 que se queja tres años

porque tiene un paisaje seco en la rodilla;

y el niño que enterraron esta mañana lloraba tanto

que hubo necesidad de llamar a los perros para que callase.

No es sueño la vida. ¡Alerta! ¡Alerta! ¡Alerta!

15 Nos caemos por las escaleras para comer la tierra húmeda

o subimos al filo de la nieve con el coro de las dalias muertas.

Pero no hay olvido, ni sueño:

carne viva. Los besos atan las bocas

en una maraña de venas recientes

20 y al que le duele su dolor le dolerá sin descanso

y al que teme la muerte la llevará sobre sus hombros.

Un día

los caballos vivirán en las tabernas

y las hormigas furiosas

25 atacarán los cielos amarillos que se refugian en los ojos de las vacas.

Otro día

veremos la resurrección de las mariposas disecadas

y aún andando por un paisaje de esponjas grises y barcos mudos

veremos brillar nuestro anillo y manar rosas de nuestra lengua.

30 ¡Alerta! ¡Alerta! ¡Alerta!

A los que guardan todavía huellas de zarpa y aguacero, a aquel muchacho que llora porque no sabe la invención del puente o a aquel muerto que ya no tiene más que la cabeza y un zapato, hay que llevarlos al muro donde iguanas y sierpes esperan,

35 donde espera la dentadura del oso, donde espera la mano momificada del niño

y la piel del camello se eriza con un violento escalofrío azul.

No duerme nadie por el cielo. Nadie, nadie.

No duerme nadie.

40 Pero si alguien cierra los ojos,

¡azotadlo, hijos míos, azotadlo!

Haya un panorama de ojos abiertos

y amargas llagas encendidas.

No duerme nadie por el mundo. Nadie, nadie. 
45 Ya lo he dicho.

No duerme nadie.

Pero si alguien tiene por la noche exceso de musgo en las sienes, abrid los escotillones para que vea bajo la luna

las copas falsas, el veneno y la calavera de los teatros.

(García Lorca 1998: 151-155)

En el poema, la “extensión” espacial característica de la world literature, en general, se evidencia primero en la situación de enunciación, marcada por una doble ambivalencia en la que se documenta un gesto casi aporético profesado por el sujeto hablante. Por un lado, la posición del sujeto de enunciación se define por un distanciamiento ostensible con respecto al escenario topográfico descrito: el texto entero carece de indicaciones deícticas precisas que pudieran permitir un posicionamiento exacto del yo lírico, procedimiento que da la impresión de que, dentro de la topografía urbana indicada en el título, el sujeto de enunciación no se ubica en ningún lugar o, por el contrario, llega a ocupar una multiplicidad de lugares diversos. ${ }^{8}$ Por otro lado, el poema consiste en gran parte en impresiones visuales concretas y se define, además, por la inserción de varias exclamaciones y apóstrofes (véanse vv. 14 y 30) que el sujeto de enunciación dirige a los habitantes de la ciudad. En el texto se efectúa, por lo tanto, una desarticulación altamente paradójica del lugar de enunciación, una deslocalización significativa, que se ve confirmada por las pocas referencias que remiten al espacio urbano (tales como "esquinas” (v. 5), “puente" (v. 32) o "muro" (v. 34)). Esta técnica, sin embargo, no sirve primeramente para producir el efecto de una pérdida de orientación del sujeto hablante, sino que sugiere, por el contrario, la omnipresencia del yo lírico en la topografía descrita. Esta omnipresencia no solo le atribuye una posición espacial que emula la posición que ocupa Dios en el universo, sino que señala, asimismo, la capacidad casi migratoria del sujeto que logra atravesar el espacio geográfico para trascender libremente las fronteras territoriales, destacando, así, el carácter globalizado del mundo empírico desplegado en el poema.

El texto, además, se presenta como el lugar de articulación de un worlding específicamente moderno, como lo demuestran notablemente las referencias al sueño. Por un lado, el poema va articulando un rechazo repetido del sueño que enfoca a los habitantes de la ciudad; ${ }^{9}$ por el

${ }^{8}$ Acerca de esta imposibilidad de ubicar el sujeto hablante en la topografía de Nueva York indicada en el título, véanse las observaciones en Friedrich (2007: 254257). Friedrich interpreta la movilidad del yo lírico como expresión de una pérdida de orientación del sujeto de enunciación y también del lector del poema.

${ }^{9}$ Véase García Lorca (1998), 151, vv. 1-2, 7-8, 38-39: "No duerme nadie por el cielo. Nadie, nadie. / No duerme nadie". 
otro, el propio texto adopta gradualmente el carácter de una visión apocalíptica dentro de la que se perfilan los contornos de su "mundialidad" particular. Estas referencias ambivalentes al sueño (en su doble sentido léxico, que denota tanto el estado del durmiente como la visión onírica) articulan de manera paradigmática una confrontación crítica con la vanguardia surrealista europea. En su conferencia "Imaginación, inspiración, evasión” (García Lorca 1984b), Lorca formula una crítica al concepto de écriture automatique, que, según André Breton, tiene por objetivo efectuar la transmisión inmediata de los mecanismos del subconsciente. ${ }^{10} \mathrm{El}$ autor opone este concepto a una lógica poética específica, que se sustrae al control racional, sin renunciar simultáneamente a las operaciones de la conciencia. Siguiendo el modelo de numerosos artistas y poetas españoles (entre ellos, Rafael Alberti o Vicente Aleixandre) vinculados al movimiento francés del surrealismo, sin que por ello adopten sus hipótesis teóricas (cf. Morris 1972), Lorca recurre deliberadamente a la representación fantasmática de la sexualidad, de actos traumáticos de violencia o de una corporalidad de naturaleza grotesca, como también a la representación surrealista de una realidad fragmentada o a la combinación de elementos de la realidad heterogéneos e incompatibles entre sí. De esta forma, en el texto aparecen numerosas imágenes surreales que se evidencian, por ejemplo, en las metáforas de colores (los "cielos amarillos" (v. 25) o el “escalofrío azul” (v. 37)). Estas, de conformidad con varios textos del Romancero gitano y con la definición de la metáfora formulada en la célebre conferencia sobre Góngora, logran establecer una conexión entre realidades opuestas y separadas. ${ }^{11}$ Hay que mencionar igualmente las imágenes de las hormigas y los ojos de la vaca en los que se refleja el cielo, imágenes que, posiblemente, presentan alusiones indirectas a la película $U n$ chien andalou (producida en 1929 por Buñuel y Dalí), en la que las hormigas simbolizan las metamorfosis de las propias imágenes oníricas del cine y el ojo cortado denota tanto la ruptura con las convenciones habituales de la percepción visual como la transgresión o la ruptura violenta de la analogía entre microcosmos y macrocosmos (cf. Edwards 1991: 41-60), señalada en el famoso match-cut fílmico al inicio de la película, que postula de modo sumamente irónico una analogía entre el ojo humano (microcosmos) y la luna (macrocosmos). Se puede inferir que en el texto poético la

${ }^{10}$ Acerca de esta crítica, véase también Friedrich 2007: 260. La recepción española del movimiento surrealista francés se perfila notablemente en los documentos reunidos en Ilie 1969: 255-336 y Brihuega 1982: 276-315.

${ }^{11}$ Véase García Lorca 1984b: 101-102: "La metáfora une dos mundos antagónicos por medio de un salto ecuestre que da la imaginación”. Acerca de la definición de la metáfora que, según Lorca, funciona como principio poético de composición, véase, entre otros, Dirscherl 1987: 87-93. 
paradoja del rechazo y de la simultánea realización textual de una visión onírica sirve para articular una reflexión metapoética que va articulando una poiesis del mundo eminentemente transcultural que, por ende, logra trascender las fronteras de su propio espacio de producción por medio de una adaptación deliberada de la poética y política representada por la vanguardia europea de las primeras décadas del siglo xx.

Esta confrontación con estructuras "poiéticas" del worlding o con conceptos del mundo y formas de saber en las que se documenta un continuo trabajo de "traducciones" se ve confirmada de nuevo en el nivel semántico del texto. El poema se define por una oposición espacial muy marcada, en la que se articula un modelo cosmológico definido por el contraste pronunciado entre cielo y mundo, formulado de modo explícito en las primeras estrofas del texto. Aunque no quede claro de qué modo concreto esta oposición espacial se refiere a la topografía urbana, se puede constatar que se efectúa una confrontación extensiva con versiones de la cosmología cristiana que marcan la cultura española del Siglo de Oro. Así, la frase "No es sueño la vida" (v. 14) se refiere ostensiblemente de modo negativo a la pieza calderoniana La vida es sueño (cf. Friedrich 2007: 258259; Koppenfels 1998: 167-171), que presenta una articulación del cosmos como theatrum mundi definido por papeles teatrales cuya distribución fija (efectuada por el director, Dios) va destacando los principios de organización social que rigen la formación tradicional de sociedades de diferenciación estratificadora, opuesta a sistemas sociales modernos con diferenciación funcional. ${ }^{12}$ La referencia metatextual, por lo tanto, contiene implicaciones políticas que llegan a identificar el texto como paradigma de una literatura mundial que va reflexionando sobre su propio estatus como "relación social" (en la línea de Franco Moretti).

En el poema, este modelo del mundo que proviene de la tradición española del Siglo de Oro se ve complementado por otro modelo topológico que no se sitúa en el horizonte de referencia ibérico, sino que retoma un concepto propagado en la literatura italiana que presenta otra forma del worlding que constituye la "mundialidad" particular del poema. Los últimos versos de la tercera estrofa - "y al que le duele su dolor le dolerá sin descanso / y al que teme la muerte le llevará sobre sus hombros” (vv. 20-21) - aluden de manera altamente irónica a la representación literaria del infierno presentada en la Divina Commedia, de Dante Alighieri, y remiten en particular al sistema de castigo del contrappaso, según el cual este va repitiendo mimética y eternamente el pecado perpetrado por el pecador. La topografía urbana de Nueva York se transforma, por lo tanto, en un espacio infernal, poblado por muertos, que se sitúa, así, de nuevo

${ }^{12}$ Acerca de la distinción sistemática entre sistemas sociales de diferenciación estratificadora y funcional, véase, de modo ejemplar, Luhmann 1987. 
en el marco de referencia proporcionado por la cosmología política de origen cristiano.

Además de los ejemplos citados, el texto contiene aún numerosas alusiones complementarias a cosmologías tradicionales, que se muestran con mayor evidencia en las referencias zoológicas que atraviesan el poema en su totalidad. Si en la mayoría de los casos se trata de animales (tales como “vacas" (v. 25) o "caballos" (v. 23)) que viven en las metrópolis o en el mundo occidental y que, según la zoología política repartida en este último y reconstruida de modo tipológico por Deleuze y Guattari en Mil mesetas, pertenecen a la categoría de los familiares o domésticos, que sirven frecuentemente para simbolizar y estabilizar las estructuras y jerarquías sociales de la comunidad humana, ${ }^{13}$ la topografía urbana imaginaria presenta igualmente algunos "exóticos" (como "iguanas" (v. 4) y "cocodrilos" (v. 6)), en los que se delinean los contornos de una cosmología animista cuyos actores ya no se integran ni en la ontología ética ni en el sistema comunitario representado por el cristianismo. Por medio de ello, las referencias a animales llegan a trazar un sistema de coordenadas geográficas que no se limita al espacio europeo, sino que va incluyendo igualmente los territorios de África y América Latina. Se puede inferir, por lo tanto, que el texto realiza un worlding etnográfico que, por sus extensiones geofísicas, por último, logra representar las demarcaciones del mundo geopolítico en su casi totalidad, llegando, mediante las transformaciones de cosmologías diversas, a confirmar su carácter verdaderamente "mundial” o "global”.

Además, la música desempeña un papel importante con respecto a la poiesis mundial del texto. Las repeticiones de frases que recuerdan a refranes en canciones (en particular, en las dos primeras y en la última estrofa) indican que el texto se distingue por la apropiación deliberada de varias estructuras musicales. Eso no parece sorprendente, ya que, desde principios de los años 20, Lorca no solamente colaboró estrechamente con el compositor Manuel de Falla, sino que también se dedicó a la música de la vanguardia (como la de Debussy) y a diversas variantes del jazz norteamericano, que, tanto para él como para muchos otros poetas de la vanguardia española (por ejemplo, Guillermo de Torre), incorporaba de modo paradigmático una expresividad rítmica y dinámica, y parecía íntimamente vinculado con el movimiento cultural de la Harlem Renaissance en Nueva York. ${ }^{14}$ Mientras que críticos contemporáneos (como Sebastià Gasch) estiman el jazz sobre todo por su "violencia rítmica extraordinaria” (Gasch

${ }^{13}$ Sobre las premisas e implicaciones de esta "zoología política” que define relaciones diversas entre animal y humano, véanse Von der Heiden/Vogl 2007: 7-12; Deleuze/ Guattari 1994: 239-316.

${ }^{14}$ Acerca del papel central que desempeña la música en la poesía de Lorca, véase, de modo paradigmático, Friedrich 2007: 269-293. 
1931), que corresponde a los ritmos pulsantes de la vida de las metrópolis, en Lorca se nota una preferencia por las tradiciones musicales surgidas de la cultura popular andaluza, incorporadas de modo prototípico en el “primitivo canto andaluz llamado 'cante jondo”" (García Lorca 1984a), que expresa un aura de lo original y de lo auténtico. Para Lorca, por ende, el jazz presenta el correlato moderno inmediato del cante jondo, como lo sugiere de modo conciso la "Conferencia recital [de FGL] sobre Poeta en Nueva York": "Y salen los negros con sus ritmos que yo descubro típicos del gran pueblo andaluz, negritos sin drama que ponen los ojos en blanco y dicen: 'Nosotros somos latinos"” (García Lorca 1990: 169). Por eso no es inesperado que en el texto lírico no sea la rítmica abrupta del jazz, sino la dinámica continua de la música popular, la que domine y, según las críticas más recientes, confiera al poema entero el carácter de una canción de cuna o de una canción infantil (cf. Koppenfels 1998: 158-172). No obstante, con respecto a la colección Poeta en Nueva York, se puede constatar que son justamente las referencias musicales las que constituyen otra red de coordenadas geoculturales con sus propios actores, trayectorias de transmisión y centros de comunicación. Por medio de la reconstrucción implícita de movimientos migratorios históricos y contemporáneos, el texto logra conectar el espacio cultural ibérico o europeo con los continentes de África y de América del Norte y crea, así, una densa red de interferencias, circulaciones y entrelazamientos (trans)culturales.

Por último, el final del texto presenta otra referencia significativa a una forma estética específica que retoma ostensiblemente un modelo del mundo ya conocido. Si el poema finaliza con una metáfora teatral que remite nuevamente a la concepción del theatrum mundi y a la relación dialéctica entre engaño y desengaño implicada en ella, esta dialéctica, sin embargo, ya no simboliza de ningún modo las operaciones de la providencia divina o el desengaño del más allá, sino que revela, por el contrario, que en la escena teatral, como también bajo ella, no se descubren otros fenómenos que los meros accesorios teatrales que van dominando el mundo entero. Este se revela gradualmente regido por un engaño generalizado que combina el recurso a la cosmovisión tradicional barroca proveniente del Siglo de Oro español con la forma del sueño surrealista de origen francés y crea, así, una interconexión transnacional y global que, por reunir el pasado con el presente, se manifiesta al mismo tiempo como una interferencia transtemporal.

\section{Conclusión}

Para concluir, se puede decir que las técnicas y procedimientos "poiéticos" del worlding que se evidencian en la poesía de Lorca se manifiestan de modo ejemplar a través de las diferencias centrales entre los géneros poé- 
ticos del Romancero gitano y del ciclo Poeta en Nueva York. Este último obtiene su dimensión "mundial” específica al operar una inversión exacta de los procesos de circulación literarios visibles en el Romancero. Mientras que el Romancero presenta un género tradicional y nacional que, sin embargo, incluye técnicas líricas de representación eminentemente modernas y transculturales, Poeta en Nueva York, al contrario, incorpora un género moderno e internacional: la lírica de la metrópolis a la que remite. Esta remite deliberadamente a conceptualizaciones del mundo que provienen de la tradición nacional peninsular del Siglo de Oro. Pasando por una diversidad de formas de saber que comprenden referencias tanto europeas como transatlánticas y que vinculan tradiciones premodernas con las artes de las vanguardias, el texto llega a iniciar una dinámica compleja de interconexiones, transformaciones y circulaciones transculturales. En ellas se perfilan las estrategias de un worlding particular que presenta la poesía como la articulación paradigmática de una verdadera "mundialidad” que parece favorecer su recepción tanto dentro como también fuera del espacio de la cultura ibérica.

\section{BIBLIOGRAFÍA}

Braudel, Fernand (1988): Le temps du monde. Paris: Colin.

Brinuega, Jaime (1982): Manifiestos, proclamas, panfletos y textos doctrinales. Las vanguardias artísticas en España: 1910-1931. Madrid: Cátedra.

Damrosch, David (2014): "Geopoetics: World Literature in the Global Mediascape”. En: Moser, Christian/Simonis, Linda (eds.): Figuren des Globalen. Weltbezug und Welterzengung in Literatur, Kunst und Medien. Göttingen: V\&R, pp. 209-230.

- (2009): How to Read World Literature. Chichester/Malden: Wiley-Blackwell.

Deleuze, Gilles/Guattari, Félix (1994): Mil mesetas. Capitalismo y esquizofrenia. Valencia: Pre-Textos.

Dirscherl, Klaus (1987): “Lorca, Góngora und die traditionelle Romanze”. En: Iberoromania, 25, 80-131.

Edwards, Gwynne (1991): The Discreet Art of Luis Buñuel. A Reading of his Films. London/New York: Boyars.

Eisenberg, Daniel (1976): Poeta en Nueva York: historia y problemas de un texto de Lorca. Barcelona: Ariel.

EтTE, Ottmar (2012): TransArea. Eine literarische Globalisierungsgeschichte. Berlin/Boston: De Gruyter.

FRIEDRICH, Sabine (2007): Transformation der Sinne. Formen dynamischer Wabrnebmung in der modernen spanischen Großstadtlyrik. München: Fink.

García Lorca, Federico (1998): Poeta en Nueva York. Ed. María Clementa Millán. Madrid: Cátedra. 
- (1990): "Conferencia-recital de Federico García Lorca sobre Poeta en Nueva York". En: Poeta en Nueva York. Ed. Piero Menarini. Madrid: Espasa-Calpe, pp. 167-178.

- (1984a): "Importancia histórica y artística del primitivo canto andaluz llamado 'cante jondo'”. En: Conferencias, vol. 1. Ed. Christopher Maurer. Madrid: Alianza, pp. 43-83.

- (1984b): “Imaginación, inspiración, evasión”. En: Conferencias, vol. 2. Ed. Christopher Maurer. Madrid: Alianza, pp. 9-31.

García-Posada, Miguel (1981): Lorca: Interpretación de Poeta en Nueva York. Madrid: Ediciones Akal.

GASch, Sebastià (1931): “Jazz”. En: La Gaceta Literaria, 5, 98, p. 9.

Gumbrecht, Hans Ulrich (1982): "Warum gerade Góngora? Poetologie und historisches Bewusstsein in Spanien zwischen Jahrhundertwende und Bürgerkrieg”. En: Warning, Rainer/Wehle, Winfried (eds.): Lyrik und Malerei der Avantgarde. München: Fink, pp. 145-192.

Honold, Alexander (2010): "Literatur in der Globalisierung - Globalisierung in der Literatur". En: <http://www.germanistik.ch/publikation.php?id=Literatur _in_der_Globalisierung $>$ (última visita: 30/11/2016).

Ilie, Paul (1969): Documents of the Spanish Vanguard. Chapel Hill: University of North Carolina Press.

Kadir, Djelal (2013): "World Literature: The Allophone, the Differential, and the Common”. En: Modern Language Quarterly, 74, 2, pp. 293-306.

- (2004): “To World, to Globalize - Comparative Literature's Crossroads". En: Comparative Literature Studies, 41, pp. 1-9.

Koppenfels, Martin (1998): Einfübrung in den Tod. García Lorcas New Yorker Dichtung und die Traner der modernen Lyrik. Würzburg: Königshausen \& Neumann.

Luhmann, Niklas (1987): Soziale Systeme. Grundriss einer allgemeinen Theorie. Frankfurt am Main: Suhrkamp.

Millán, María Clementa (1998): “Introducción”. En: García Lorca, Federico: Poeta en Nueva York. Madrid: Cátedra, pp. 19-53.

Moretti, Franco (2003): “More Conjectures”. En: New Left Review, 20, pp. 7381.

— (2000): “Conjectures on World Literature”. En: New Left Review, 1, pp. 1-12. Morris, Cyril Brian (1972): Surrealism and Spain. 1920-1936. Cambridge: Cambridge University Press.

Schüttpelz, Erhard (2009): "Weltliteratur in der Perspektive einer Longue Durée I: Die fünf Zeitschichten der Globalisierung”. En: Ezli, Özkan/Kimmich, Dorothee/Werberger, Annette (eds.): Wider den Kulturenzwang. Migration, Kulturalisierung und Weltliteratur. Bielefeld: transcript, pp. 339-360.

SiebenmanN, Gustav (1998a): “Zu Lorcas Rezeption in Lateinamerika”. En: Briesemeister, Dietrich/Schönberger, Axel et al. (eds.): Ex nobili philologorum officio: Festschrift für Heinrich Bible zu seinem 80. Geburtstag. Berlin: Domus Ed. Europaea, pp. 501-512. 
— (1998b): "Federico García Lorcas Amerika-Erfahrungen”. En: Iberoromania, 48 , pp. 1-15.

Von der Heiden, Anne/Vogl, Joseph (eds.) (2007): Politische Zoologie. Zürich/ Berlin: Diaphanes.

Wallerstein, Immanuel Maurice (2004): World-Systems Analysis: An Introduction. Durham: Duke University Press. 